\title{
QUINZE MILHÕES DE ESPELHOS: \\ REFLEXÕES SOBRE CRIAÇÃO, PERFORMACES E REDES EDUCATIVAS EM BLACK \\ MIRROR
}

FIFTEEN MILLION MIRRORS:

REFLECTIONS ON CREATION, PERFORMACES AND EDUCATIONAL NETWORKS

IN BLACK MIRROR

QUINCE MILLONES DE ESPEJOS:

REFLEXIONES SOBRE CREACIÓN, DESEMPEÑO Y REDES EDUCATIVAS EN BLACK

MIRROR

Marco Aurélio Correa ${ }^{1}$

\begin{abstract}
RESUMO
Spoilers vem a frente, mas não é nenhuma novidade. Neste texto apresentamos reflexões, espelhamentos e pensamentos sobre o episódio 15 Millions Merits, da série Black Mirror. No universo da série, cada episódio retrata um presente alternativo ou um futuro próximo onde os seres humanos tem uma relação sarcástica, desconfortável e controversa com a tecnologia. O universo fictício da série reflete as nossas tensões atuais entre o consumo e a criação com a tecnologia. Usaremos a narrativa da série como intercessores de nosso pensamento. Desta forma, iremos pensar como as relações sobre a produção de conhecimento na modernidade, refletem em nossa sociedade consumista na atualidade. Pensando em formas de não dominação, nem cooptação e apropriação, enfatizando a criação artística como performance de um corpo sem órgãos que subverte rizomaticamente as hegemonias. Encontrando na educação, com protagonistas os professores e educandos germes de resistência as práticas controladoras curriculares que refletem a dominação mercadológica dos tempos atuais.
\end{abstract}

PALAVRAS-CHAVE: Criação. Audiovisualidades. Tecnologias, Performances. Redes Educativas.

\begin{abstract}
Spoilers come forward, but it's nothing new. In this text we present reflections, mirrors and thoughts about episode 15 Millions Merits of the Black Mirror series. In the show's universe, each episode portrays an alternate present or near future where humans have a sarcastic, uncomfortable, and controversial relationship with technology. The fictional universe of the series reflects our current tensions between consumption and creation with technology. We will use the narrative of the series as intercessors of our thinking. In this way, we will think how the relations on the production of knowledge in modernity, reflect in our consumerist society today. Thinking about forms of non-domination, nor co-optation and appropriation, emphasizing the artistic creation as performance of an organless body that rhizomatically subverts hegemonies. Finding in education, with protagonists the teachers and students of resistance germs the curricular controlling practices that reflect the
\end{abstract}

Submetido em: 28/08/2019 - Aceito em: 29/11/2019 - Publicado em: 28/12/2019.

${ }^{1}$ Graduado em Pedagogia pela UERJ. 
market domination of the present times.

KEYWORDS: Creation. Audiovisualities. Technologies, Performances. Educational networks.

\section{RESUMEN}

Los spoilers se presentan, pero no es nada nuevo. En este texto presentamos reflexiones, espejos y pensamientos sobre el episodio 15 Millones de méritos de la serie Black Mirror. En el universo del programa, cada episodio retrata un presente alternativo o un futuro cercano donde los humanos tienen una relación sarcástica, incómoda y controvertida con la tecnología. El universo ficticio de la serie refleja nuestras tensiones actuales entre el consumo y la creación con la tecnología. Utilizaremos la narrativa de la serie como intercesores de nuestro pensamiento. De esta manera, pensaremos cómo las relaciones sobre la producción de conocimiento en la modernidad, se reflejan en nuestra sociedad consumista de hoy. Pensando en formas de no dominación, ni cooptación y apropiación, enfatizando la creación artística como la actuación de un cuerpo sin órganos que rizomáticamente subvierte las hegemonías. Encontrando en la educación, con protagonistas a los maestros y estudiantes de gérmenes de resistencia, las prácticas de control curricular que reflejan el dominio del mercado de los tiempos actuales.

PALABRAS CLAVE: Creación Audiovisualidades. Tecnologías, Actuaciones. Redes educativas.

\section{INTRODUÇÃO}

Spoilers vem a frente, mas não é nenhuma novidade. Vivemos em tempos onde é quase impossível ficar distante de alguma tela preta durante muito tempo. Estas telas pretas que nos acompanham buscam sempre conseguir refletir nossos desejos para obter nossa atenção. Devido aos tempos acelerados e solitários que vivemos, encontramos na tela o afago para nossa carência afetiva. Mas será que sempre estas telas espelham o que queremos para nossas vidas ou apenas estamos sendo iludidos por algum grande ilusionista ganancioso? Mas será que esse grande ilusionista é igualmente carente a nós e busca na atenção dos outros, a aceitação, o lucro e o poder que o satisfaz?

"Nós estamos carentes de utopias e plenos de crises". (NOGUERA, 2017, s/p) Precisamos pensar em nossa relação com a tecnologia, das que forma consumimos a tecnologia, dos usos que fazemos dela, ao invés de somente consumir sem reagir.

A criação de conhecimentos estabelecida pela modernidade criou um distanciamento do reconhecimento da inventividade nos cotidianos. Deixando só com a razão do cientificismo o domínio do criar, relegando as artes, performances e outras formas de criar o espaço do ócio, 
do lúdico, do improdutivo.

Entendendo que as ideias em ciências na Modernidade implantaram a compreensão de que o conhecimento se constrói com as pesquisas desenvolvidas pelos cientistas dentro da metáfora da árvore (Lefebvre, 1983), vimos que a criação dos conhecimentos nos cotidianos era feita em redes, segundo esse mesmo autor. Desse modo, nas pesquisas com os cotidianos, adotamos a ideia de que os conhecimentossignificações são tecidos. Percebemos, então, que ao mesmo tempo em que tecemos conhecimentos, tecemos significações para os mesmos que os explicam e nos dizem do valor que têm para o viver cotidiano. (ALVES, FERRAÇO e SOARES, 2017, p. 11)

Porém, sabemos "que todo trabalho de arte move, física ou mentalmente, aquele que se deixa tocar por ele" (TINOCO, 2009, p. 238). Desta forma encararemos neste artigo a série Black Mirror, principalmente o episódio 15 Million Merits como intercessores do nosso pensamento, como personagens conceituais que segundo Deleuze e Guattari:

\footnotetext{
Os personagens conceituais têm este papel, manifestar os territórios, desterritorializações e reterritorializações absolutas do pensamento. Os personagens conceituais são pensadores, unicamente pensadores, e seus traços personalísticos se juntam estreitamente aos traços diagramático do pensamento e intensivos do conceito.

(1992, p. 84)
}

Assim, vamos pensar como as impressões ao assistir este episódio de Black Mirror podem fazer reflexões em nosso modo de como encarar a sociedade, pensando principalmente a presença da educação, dos professores e dos educandos como artistas, performadores e criadores de sentidos diversos e disruptivos as práticas hegemônicas contemporâneas. Ações do campo dos rizomas, criações horizontais e coletivas que a dupla francesa contempla em:

\footnotetext{
Um rizoma não começa nem conclui, ele se encontra sempre no meio, entre as coisas, inter-ser, intermezzo. A árvore é filiação, mas o rizoma é aliança, unicamente aliança. A árvore impõe o verbo "ser", mas o rizoma tem como tecido a conjunção "e... e... e..." Há nesta conjunção força suficiente para sacudir e desenraizar o verbo ser. [...] Entre as coisas não designa uma correlação localizável que vai de uma para outra e reciprocamente, mas uma direção perpendicular, um movimento transversal que as carrega uma e outra, riacho sem início nem fim, que rói suas duas margens e adquire velocidade no meio. (DELEUZE, GUATTARI, 1995, p. 36)
}

O que nos importa aqui não é só o que a série nos mostra, mas o que fazemos com o que ela nos apresenta.seria impossível dissecar cada quadro, cada ambiguidade e cada sacada da 
série, por isso decidimos focar em um episódio, mas mesmo assim pincelando pelo universo coletivo da série.

\section{BLACK MIRROR E QUINZE MILHÕES DE MÉRITOS}

Black Mirror é uma série britânica de ficção científica em formato de antologia onde cada um de seus episódios vive uma realidade supostamente isolada uma da outra. A série aborda temas contemporâneos examinando a sociedade atual particularmente com atenção as consequências não antecipadas do uso das novas tecnologias. Os episódios se situam em um presente alternativo ou um futuro próximo especulativo. Black Mirror segue o legado de The Twilight Zone (Além da imaginação no Brasil), série estadunidense que lidou fantasiosamente com questões polêmicas nos anos 1960 para escapar da censura, abordando assim questões problemáticas da inserção da tecnologia em vários âmbitos da vida contemporânea e dos usos controversos destas novas tecnologias nos cotidianos. A série normalmente transita entre tom sarcástico bem humorado ou um tom sombrio aterrorizante criando uma sensação de desconforto por sentirmos que parte de nossa vida atual já poderia ser vista por outras gerações como um futuro distópico.

O sarcasmo, a ironia e o humor, segundo Deleuze são formas de transgressão à hegemoneidade:

a primeira maneira de reverter a lei é irônica, a ironia aí aparecendo como arte dos princípios, da ascensão aos princípios e da reversão dos princípios. A segunda é o humor, que é uma arte das consequências e das descidas, das suspensões e das quedas. Significa isso que a repetição surge tanto nesta suspensão quanto nesta ascensão, como se a existência se retomasse e se "reiterasse" em si mesma desde que já não seja coagida pelas leis? A repetição pertence ao humor e à ironia, sendo por natureza transgressão, exceção, e manifestando sempre uma singularidade contra os particulares submetidos à lei, um universal contra as generalidades que estabelecem a lei. (Deleuze, 2000, p. 14-15 apud ALVES; BRANDÃO, 2017, p. 100).

A série traz discussões complexas intricadas, mesmo que subjetivamente, em seus episódios para o entretenimento cotidiano. Possibilitando que um espectador casual, sem muitas 
intenções de desenvolver um argumento ou uma crítica, reflita sobre aspectos profundos de sua vida cotidiana. Uma das interpretações do nome da série, Espelho preto, seria que cada fria tela brilhante, como uma TV, um monitor, ou um smartphone presentes em nossos cotidianos pode refletir um mundo nosso distorcido cheio de controversas. Esta é a grande sacada da série ao brincar com uma realidade distante e distópica mas dentro dos nossos padrões atuais na relação com o consumo e o uso das tecnologias.

O episódio da série Black Mirror "15 Million Merits" conta a história de um mundo num futuro distópico onde Bing, um de seus habitantes, vive uma vida de repetição e marasmo. Bing e seus colegas de trabalho - e praticamente todo mundo que habita esse universo criado - vivem para trabalhar pedalando em uma bicicleta em troca de merits, a moeda local. Com esses merits eles podem comprar praticamente tudo que sua sociedade que os oferece desde comida até pequenos adereços para os avatares que são a representação digital das pessoas no mundo virtual que controla os trabalhadores. O cômodo onde os trabalhadores moram é um cubículo cercado de telas interativas que estão constantemente oferecendo produtos, vídeos ou adereços para os trabalhadores a partir do que eles estão pensando. A vida dos moradores desse local praticamente é feita em pedalar para consumir os entretenimentos sensacionalistas que o sistema oferece. Bing parece estar desiludido de viver em um mundo com prazeres fúteis e que a chacota com os que não pedalam, os acima do peso, é constante.

A única satisfação de Bing é quando ele ouve uma colega de trabalho, Abi cantarolar no banheiro, o jovem fica tão emocionado com a beleza de seu canto que insiste para a moça aceitar o dinheiro que tinha recebido de herança da morte de seu irmão, 15 milhões de merits, e tentar a sorte no programa de palco Hot Spot, uma espécie de The Voice deste universo. A menina decide aceitar a proposta de Bing, que não via utilidade em seu dinheiro, e vai ao programa. Ao conseguir a vaga ela é induzida a tomar uma substância estranha. Ao cantar sua música ela acaba não convencendo por completo os jurados sobre sua qualidade como cantora, então um dos jurados oferece a ela pelos seus atributos físicos uma vaga na carreira de pornografia adulta, programa que também é frequente na programação do sistema. 


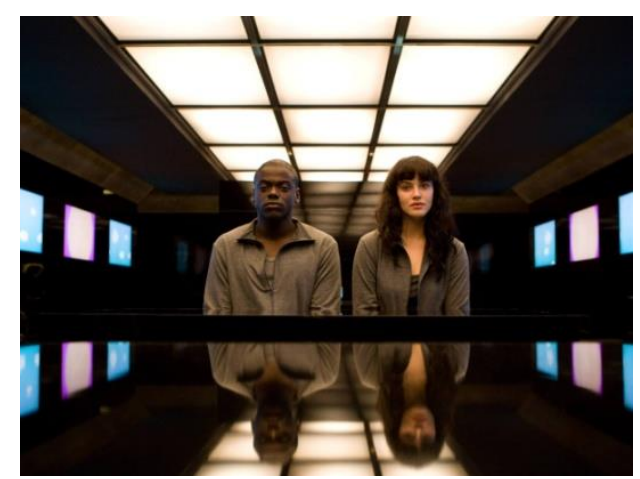

Figura 1. Bing e Abi à procura da felicidade Fonte:[https://bit.ly/2ZVv8Vb]

Bing quando descobre que Abi aceitou o convite fica mais ainda desiludido e desapontado com a vida. E o pior, vê frequentemente sua musa nas propagandas de seu programa pornográfico, só que agora o jovem não tem mais dinheiro para pular os anúncios. Frustrado por completo Bing tenta um ultimato. Começa a se jogar contras as paredes de seu minúsculo cubículo de moradia na tentativa de fugir daquele mundo. Com sua insistência Bing consegue quebrar as telas das paredes e se corta num caco de vidro, o jovem fica pensativo após ver o sangue. Após juntar novamente os 15 milhões dedicando sua vida completamente ao trabalho na bicicleta o jovem vai ao programa de auditório executar algum plano.

Ao chegar no palco e ter sua vez de se apresentar Bing faz um show de dança para enganar os jurados até que quando consegue a total atenção da platéia ameaça tirar a sua vida com um dos cacos que ele guardou. Bing faz um discurso mostrando toda a sua insatisfação e descontentamento para com o sistema e contra a hipocrisia e a apatia dos jurados e de outros trabalhadores espectadores. Reproduzo aqui o discurso:

Eu não tenho um discurso, eu não planejei palavras, eu nem cheguei a tentar isso. Eu só sabia que eu tinha que vir aqui, ficar aqui e eu sabia que queria que vocês ouvissem; realmente ouvissem, não só fazer uma cara como se estivessem escutando, como vocês fazem nas outras vezes. Uma cara como se vocês estivessem sentindo ao invés de processar. Vocês fazem uma cara e apontam pro palco e la-la-la nós cantamos e dançamos e caímos por ai e tudo que vocês vêem ai de cima, não são pessoas, vocês não vêem pessoas ai de cima, é tudo forragem. E quanto mais falsa a forragem mais vocês amam porque forragem falsa é a única coisa que funciona qualquer que seja, forragem falsa é tudo que nós podemos digerir - realmente não por completo. Dor real, vício real, que nós podemos tomar. É, enfia um homem gordo num 
posto e nós iremos rir ferozmente porque nós ganhamos o direito, nós cumprimos tempo de cadeia e ele é a escória descuidada então nós podemos ha ha ha dele. Porque nós estamos tão fora de si com desesperado que nós não conhecemos nada melhor. Tudo o que conhecemos é forragem falsa e comprar besteiras. É como nós falamos com uns aos outros, como nos expressamos é comprando besteira. Eu tenho um sonho? O pico de nossos sonhos é um novo chapéu para o nosso doppel, um chapéu que nem exista. Não está nem aqui, nós compramos coisas que não estão nem aqui. Nos mostrem alguma coisa real e livre e lindo, vocês não pode. Isso nos quebraria, nós somos muito dopados pra isso, nossas mentes iriam sufocar. Existe apenas tantas maravilhas o quanto podemos aguentar, é por isso quando vocês acham alguma maravilha qualquer que seja vocês oferecem isso em porções escassas, e só então até que esteja aumentado e empacotado e enfiado através dez mil filtros pré assinados, até que seja nada mais que uma série sem sentido de luzes, enquanto nós montando dia vai, dia vem indo pra onde? Carregando o que? Todas as pequenas celas em pequenas telas e grandes celas em grandes telas e se ferrem vocês. Se ferrem vocês, é por isso que isto ferve tudo para ferrar vocês. Se ferrem por sentar ai e lentamente costurarem as coisas pior. Se ferrem e seus holofotes e suas caras santas e se ferrem todos vocês por tirarem a única coisa que eu um dia cheguei perto de ser real sobre qualquer coisa. Por escorrer por ai e quebrar como um osso, como uma piada, mais uma piada horrorosa em um reino de milhares e então se ferrem. Se ferrem por acontecerem. Se ferrem vocês por mim, por nós, por todos, se ferrem! (BLACK MIRROR, 2016, s/p, tradução livre do autor)

No fim, vemos Bing nas telas que acompanham as bicicletas e nos cubículos dos trabalhadores agora fazendo seu discurso de ódio contra o sistema cotidianamente. O público tão alienado com a rotina de trabalho para o consumo não entendeu todas suas críticas. Enquanto isso o jovem vive num quarto muito maior do que antes e com uma vida para uma verde floresta.

\section{REFLETINDO À TEORIA}

A série Black Mirror e principalmente o episódio "15 Million Merits" nos promovem a reflexão sobre diversos aspectos de nossa realidade e também da forma como interagimos e consumimos as nossas produções estéticas. Os cinemas, as narrativas e todas as audiovisualidades nos permitem essa possibilidade de reflexão sobre uma produção, mas a ficção científica, distópica ou não, sempre nos permite ir um pouco a além da nossa vida 
cotidiana, apesar de que muitas ficções científicas partem das controvérsias de nossas realidades para especular invenções tecnológica, outras realidades e possíveis futuros.

Black Mirror tem como mote principal exatamente como centralidade a imaginação de futuros não tão distantes, o que é uma ruptura com a proposta inicial das audiovisualidades que buscavam através de um projeto ocidental, desde as artes cênicas da Grécia antiga alguma forma de capturar o real. Retratando a realidade além das limitações dos espaçostempos ${ }^{2}$.

Não é à toa que o cinematógrafo dos irmãos Lumière, primeira tecnologia que conseguiu capturar fidedignamente as imagens em movimento, tem em suas primeiras filmagens cenas corriqueiras do cotidiano. Em seguida as primeiras filmagens se expandiram para as variedades, cenas exóticas de lugares distintos ou apresentações artísticas especificas, além de servir como jornais de notícias que eram exibidos em cinemas. Ou seja a proposta do cinema em seus primeiros momentos era dar continuidade ao projeto ocidental moderno da perfeição científica, conseguindo representar a realidade através da filmagem cinematográfica. Porém, foi exatamente com essa ambição que em que fora decretada "a crise do projeto racionalista do ocidente" (GUÉRON, 2011, p. 16).

$\mathrm{O}$ cinema, principal manifestação audiovisual dos primeiros anos do século $\mathrm{XX}$, buscando uma potência do real percebeu que o que era rentável financeiramente não eram as meras tentativas de representação do real, do corriqueiro, mas sim a dramatização de temas frequentes em nossos cotidianos. Aliado ao projeto de nação estadunidense, Hollywood desponta como expoente de produção audiovisual mundial exportando para todo o mundo o sentido de mundo dos Estados Unidos da América (GUÉRON, 2011).

Embasado por diversos campos de estudo, os dramas do cinema estadunidense conquistam todo o mundo. Usando da psicologia para conseguir criar um encantamento e disparar o desejo da audiência pela realidade inventada de suas estrelas, Hollywood se torna uma máquina de sonhos, uma industria da potência do falso. Sabemos que o que vemos nas telas de cinema não são reais, mas ao assistir um filme muitas vezes nos esquecemos que estamos

\footnotetext{
${ }^{2}$ Espaçostempos aparecem juntas, no plural e em itálico por proposta epistemológica das pesquisas com os cotidianos (ALVES; FERRAÇO; SOARES, 2016) como forma de evidenciar que não existem dicotomias, como no pensamento cientificista moderno, entre o espaço e o tempo, dentre outros conceitos comumente opostos.
} 
assistindo algo. Os filmes são produções feitas por seres humanos, através de sua interpretação sobre a realidade, por isso que nos usar dos filmes como intercessores de nossa realidade (GUÉRON, 2011).

O episódio 15 Million Merits é um grande intercessor para pensamos sobre a criação humana como interpretação da realidade. Existe criação sem interpretação? Existe criação sem intercessão? A autenticidade é algo que está em xeque no decorrer do episódio em questão. Os elaboradores do episódio partem da supressão para apresentar o universo onde os personagens estão inseridos, não sabemos mais do pouco que nos é apresentado sobre a vida dos personagens. Só sabemos que Bing e a maioria dos personagens secundários tem uma vida de trabalho e consumo constante. Eles pedalam para produzir energia, sem sabermos a finalidade dela, mantendo assim o seu corpo em forma e não precisam trabalhar na limpeza, como as pessoas de macacão amarelo, todas acima do peso, que são continuamente desprezadas. O trabalho consiste pedalar em um ambiente virtual, sendo bombardeado por publicidades e programas de televisão. A publicidade cerca a vida neste universo, os quartos dos trabalhadores são um cubo onde todas as paredes são como uma tela de um smartphone.

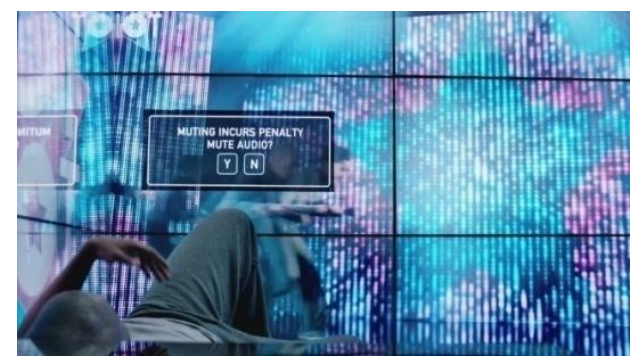

Figura 2. Bing e seu mundo espelhado Fonte:[ https://bit.ly/2KxALU9]

O universo de 15 Million Merits leva ao extremo o ode das sociedades ocidentais para com o trabalho, retornando o cientificismo o trabalho se configuraria na modernidade capitalista como uma transição a salvação religiosa para a salvação mercadológica. Noguera (2017, s/p) aponta que "o trabalho é a punição divina que vai perseguir o ser humano indefinidamente. Desse modo, apesar de ser penoso e doloroso, o trabalho passaria a ser uma constante em todas as sociedades, uma atividade inescapável e sem a qual não poderíamos sobreviver". O 
culto de 15 Million Merits é ao trabalho e ao consumo, assim como a sina do neoliberalismo contemporâneo. Noguera (2017, s/p) ainda acrescenta, "com efeito, considerando uma determinada perspectiva teológica e o pensamento marxista, o trabalho seria a possibilidade de redenção. Porque está no princípio da condição humana".

A única possibilidade de criação dos personagens que temos contato está na ornamentação de seus avatares, ou então no sucesso da vida artística, que está completamente alinhada ao julgo dos juízes do programa de auditório. Nenhum dejeto escapa da árdua limpeza dos macacões amarelo, os objetos que Bing consegue esconder são primordiais pro andamento do enredo. $\mathrm{O}$ pinguim feito por Abi é o artefato que representa a criatividade naquele mundo de consumo e propaganda.

A autenticidade da persona de Abi é o grande diferencial na trama de Bing, pois ele encontra na mulher a invenção de uma criatividade diferente das outras, porém, pelo poder da publicidade ele acha que a emancipação de Abi estaria no show de talentos. O que acaba dando errado, pois no julgamento dos jurados ela era apenas mediana.

Bing depois de preparar a sua vingança treina para conseguir um discurso original, autêntico que iria fazer com que os jurados e o público se atentasse a realidade alienante que eles vivem, porém, seu grito por consciência acaba sendo cooptado também. No final encontramos Bing vivendo em uma sala bem mais do que o seu antigo cubículo, mas as paredes também são de vidro, então será que nem a grande e verde floresta que agora o cerca é verdadeira?

$\mathrm{Na}$ realidade espelhada e expandida em 15 Million Merits vemos como "o projeto civilizatório baseado no trabalho é autodestrutivo" (NOGUERA, 2017, s/p), percebemos a como é necessário que exista uma dominação em todos os âmbitos que podem representar uma ameação a estabilidade do sistema de dualidade entre o trabalho e o consumo. A nossa sociedade contemporânea já chegou a um ponto que consegue cooptar movimentos de insurgência, como forma do próprio aparato de dominação, como podemos ver no mundo midiático das publicidades.

É de suma importância que grandes empresas sejam afetadas pelos movimentos sociais que reivindicam melhoras para a vida coletiva, como tem acontecido com os movimentos 
identitários baseados em raça, gênero, classe e sexualidade. Noguera reitera que as dominações hegemônicas junto "as políticas contemporâneas são artimanhas de disputas, sempre gestadas em perspectivas de corrupção, do racismo estrutural, do sexismo opressor, da heteronormatividade, do adultocentrismo e outras formas de dominação e opressão" (2019, p. 138). Vemos diversos exemplos de comerciais que começam a trabalhar a diversidade em suas representações, criando até narrativas polêmicas, mas que agem de forma combativa às pressões do mercado de consumo. "Nós estamos diante de uma racionalidade que articula racismo e mercado. Essa dupla face (racismo e mercado) é o elemento chave da racionalidade de toda política contemporânea neoliberal" (NOGUERA, 2019, p. 136)

15 Million Merits não aborda diretamente questões identitárias, outros episódios da série se aprofundam melhor nesta discussão, porém vemos na trama de Bing e Abi alguns pontos conflituosos. Abi para chegar a fama precisa vender o que tem de belo, Bing encontrou no seu canto a oportunidade de tirar a mulher das pedaladas sem destino, porém os jurados encontraram na beleza de Abi a chance de trocar de vida através da pornografia. Mais uma vez os corpos femininos são objetificados nas engrenagens do mercado patriarcal. Será que a escolha de Daniel Kaluuya - um homem negro - para interpretar Bing se deu somente por sua qualidade como ator? O desabafo de um homem negro teria um impacto maior, tanto na própria narrativa, como para nós espectadores contemporâneos?

São questões retóricas que não possuem uma resposta conclusiva, mas com facilidade encontramos textos sobre a relação da série Black Mirror com o que foi chamado de sofrimento negro ${ }^{3}$. Com o advento de audiovisualidades com protagonismo negro na mídia, como no caso da plataforma de streaming Netflix, se questiona o quanto é necessário o sofrimento no protagonismo negro no entretenimento contemporâneo? Será que a experiência identitária, não se limitando só a racial, precisa estar sempre usando o sofrimento e a denúncia para propor as reflexões necessária para a ruptura dos paradigmas contemporâneos?

3 Fonte: https://www.vice.com/en_us/article/mbp9my/black-mirror-is-obsessed-with-black-suffering Acesso: $13 / 0 / / 2019$. 
No episódio Black Museum ${ }^{4}$, talvez o episódio mais voltado a questão racial, o sofrimento negro como entretenimento entra como parte da filosofia da série, onde um dono de um isolado museu exibe seus itens de sua coleção de crimes tecnológicos, um dos artefatos é uma máquina onde um homem negro falsamente acusado é eletrocutado em holograma para o prazer de sádicos racistas. O episódio, assim como a série, com a sua expertise consegue se sair bem apesar de todo desconforto causado pela contradição, porém muitas inquietações ainda ficam no ar. Essa talvez seja a melhor qualidade de Black Mirror, não determinar certezas, mas sim trabalhar com a reflexão e a incerteza, deixando a ação crítica para os próprios espectadores. O que nos importa aqui não é só o que a série nos mostra, mas o que fazemos com o que ela nos apresenta.

O que nos faz retornar a questão da criação dentro das hegemonias dominantes, Noguera sabiamente define que "somos seres lúdicos, a ludicidade - o jogo e a brincadeira - é que nos define como humanos; nunca o controle e a capacidade de destruição" (2018, p. 139). Não nos cabe tentar preencher todos os vazios deixados pela série, nem tentar amarrar todos os pontos soltos deixados, mas sim de tentar refletir sobre o que vemos em nossas pequenas e brilhantes telas pretas.

Vamos focar aqui na performance que Bing faz ao final do episódio para confabular como as performances, intencionais ou não, tem um poder sobre a nossa percepção da realidade. Apesar de ter sido apropriado pelo sistema, a performance de desabafo no final do episódio é o grande momento de insurgência no universo de 15 Million Merits. É a ponta de esperança que temos que as injustiças e os desconfortos presentes no episódio terão uma reviravolta, apesar de não acontecer a virada que esperamos, já foi uma atitude ousada por si só.

A performance faz parte da gama de termos que são praticamente impossíveis de se definir, pois encontram diversas variações dependendo do contexto de atuação e da mídia de reprodução. Porém, "o termo performance foi e continua sendo empregado para designar diferentes dimensões do conjunto de práticas artísticas relacionadas ao corpo" (TINOCO, 2009 , p. 234). A corporeidade é o veículo principal quando se fala em performance. No

4 Fonte: http://www.justificando.com/2018/01/09/black-museum-aprisionamento-colonial-de-memorias-negras/ Acesso: 13/0//2019. 
cientificismo moderno, o pensamento em dualidade entre dois campos epistêmicos, como dito anteriormente, cria uma hierarquia em dicotomia, como o certo e o errado, o racional e o irracional, ver e ouvir, o sagrado e o profano e a mente e o corpo. A performance como arte, se depara com este paradigma, pois ela é basicamente uma expressão artística através do corpo, não necessariamente suprimindo a mente, mas também não fazendo necessidade de um raciocínio lógico para criar um campo semântico de entendimento. A performance, diferentemente da dança que é quase indissociável da música - uma criação do intelecto humano segundo o pensamento moderno -, não precisa por completo de um acompanhamento musical. Por tais questões, a performance cria esse estado de estranhamento e desconforto, para nossas mentes sempre em busca de uma explicação, de uma razão. A performance é a espontaneidade, o descontrole, o avesso que cria aversão no pensamento moderno. O discurso de Bing, em alguns momentos não faz nenhum sentido, da mesma forma que não conseguimos ser completamente inteligíveis quando perdemos a paciência.

O distanciamento ao corpo, provocado pela ascensão da sociedade do conhecimento e da informação, cria alguns tipos de recalcamentos no ser humano. Nos graus mais básicos este recalcamento cria em nosso imaginário coletivo uma repressão de tudo que é corporal, em prol de uma hierarquia da mente, estigmatizando os povos tradicionais do mundo não ocidentais como animalizados e bestializados por exemplo; nos desconecta de fato com nossos corpos vivos, criando recalcamentos com a própria sexualidade, causando os problemas do sexismo, da homofobia; e por último cria um culto excessivo a auto-imagem, não pensando em um corpo saudável, mas um corpo esteticamente dentro dos padrões organizados pelo mercado midiático.

É o que vemos em 15 Million Merits as pessoas exercitam seus corpos em movimentos repetidos, mecânicos, sem explorar todas as possibilidades de seus corpos, porém são constantemente bombardeados com informações visuais de diferentes mídias, inclusive as que exploram os corpos femininos com pornografia e as que fazem chacota com os acima do peso que ocupam uma classe social inferior. Bing ao ameaçar se matar, dar fim no funcionamento de seu corpo, cria esse estado de atenção nas pessoas porque aparentemente ninguém tem coragem ali de por em risco os corpos bem exercitados. 


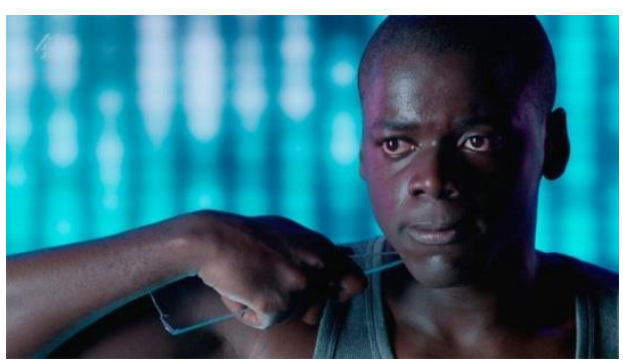

Figura 3. Corpo em risco

Fonte:[ https://bit.ly/2YPTNOI]

$\mathrm{Na}$ contemporaneidade, temos alcançado avanços em nossa corporeidade, não que tenhamos invertido o paradigma entre corpo e mente, criando uma outra hierarquia, mas sim começando a ter um contato maior com a expressividade de nossos corpos. Este movimento se inicia a partir da década de 1960, onde a questão do pertencimento identitário, a territorialização dos corpos, cria um senso de perceber os próprios corpos diferentes como artefatos políticos. Como diz Tinoco "em vez do sujeito transcendente moderno, tem-se o sujeito imanente, encarnado, desejado, aquele que assume e incorpora uma dimensão social da produção artística" (2009, p. 235).

Desde o movimento das sufragistas, o movimento Black is Beautiful ${ }^{5}$, as marchas indígenas, as paradas LGBT, até muitas outras manifestações contemporâneas a performance aparece como arte e política, criando um espaço de performação que não se limita a uma obra meramente contemplativa, mas sim uma obra que cativa os espectadores a também serem participantes, e em muitos casos até criando uma zona de indefinição entre o performador e o espectador. Tinoco discorre melhor sobre esta relação,

\footnotetext{
Elas criariam a sua volta o que Melim chama de espaço de performação, ou seja, um espaço relacional ou comunicacional que surgiria do encontro do espectador com a obra-proposição, motivando-o à ação. Ao movimentar-se em diálogo com a obra, o participador vivenciaria a ampliação, em seu corpo, da noção de performance, tornando-se um prolongamento do trabalho. A obra seria deflagradora de um movimento participativo e existiria apenas
}

\footnotetext{
${ }^{5}$ Em português, negro é lindo, foi um movimento político e cultural iniciado por afro-americanos nos EUA na década de 1960 que reverbera o mundo diaspórico até hoje buscando subverter a ideia de negritude como algo esteticamente inferior.
} 
enquanto superfície aberta à contribuição do espectador, e não como obra pronta, fechada, auto-suficiente. (2009, p. 237)

Black Mirror é exatamente isso, não é uma obra fechada somente para ser apreciada sem nenhuma forma de reflexão do espectador. Acredito que com uma visão contemplativa, a série até perca o seu caráter provocador, porque só com o incomodo de seus expectadores que a série alcança todo o seu impacto potencial. Black Mirror: Bandersnatch (2018), uma versão interativa em longa metragem da série, explora a relação entre obra e espectador, onde a narrativa do filme acontece através da interação daqueles que estão assistindo, mergulhando por completo no destino do filme.

O performador estabelece agenciamentos com o participador, que toma parte na obra e a transforma. Ao verter seu corpo em expressão direta do pensamento, ele segue a reversão sugerida por Deleuze e Guattari, para quem o corpo não é mais o obstáculo que separa o pensamento de si mesmo, aquilo que deve superar para conseguir pensar, e sim, ao contrário, aquilo em que ele mergulha ou deve mergulhar para atingir a vida (TINOCO, 2009, p. 240).

O grande problema é que muito conteúdo é produzido na internet após o impacto dos episódios da série, mas esse conteúdo é normalmente produzido e compartilhado em redes sociais que já fazem parte do sistema cooptado do capitalismo midiático. Fóruns fechados, pequenos veículos de mídia e a produção acadêmica também produzem uma significativa quantidade de material, porém, qual será a efetividade destas reflexões em nossa sociedade? Será que a série está realmente preocupada em inserir em forma de entretenimento uma discussão necessária sobre nossa relação com as novas tecnologias? Ou apenas busca cooptar e se apropriar de uma discussão importante e lucrar com isso, como o próprio Bing em 15

\section{Million Merits?}

É difícil não cair nesse paradoxo, talvez a intenção dos criadores da série seja definitivamente de que fiquemos neste embate, mas uma vez acredito que não precisamos de respostas conclusivas, pois isso seria refutar toda a linha de pensamento que estamos desenvolvendo aqui. Ao invés de cairmos nas armadilhas da dicotomia, entre pessimismo e otimismo, utopia e distopia, podemos pensar numa zona de indeterminação, onde todas essas possibilidades divergentes vivem em conflitos e nos fazem movimentar perante a uma ação naquilo que 
encontramos como nossos problemas sociais. Esta é a ideia de Corpo sem Órgãos de Deleuze e Guattari apresentada por Tinoco (2009), uma zona opaca e conflitante aos paradigmas que vivenciamos. Podemos aplicar estas questões em um possível cotidiano educativa para suscitar discussões perante aos problemas apresentados até aqui.

\title{
ESPELHANDO EM REDES EDUCATIVAS
}

Ao considerarmos as audiovisualidades artefatos imprescindíveis para a reflexão sobre a sociedade que vivemos, encontramos os cotidianos escolares como espaçostempos presentes na teia rizomática que tece nossos cotidianos, que também consomem, interagem e criam reflexões com as audiovisualidades. Uma das grandes sacadas de Black Mirror é a crítica ao mal uso ou as controvérsias presentes da entrada cada vez mais constantes das novas tecnologias em nossas vidas, sabemos que a escola vive faz tempos um embate com as tecnologias digitais que entram nela junto aos estudantes.

\begin{abstract}
Os aparelhos produtores e os meios distribuidores de sons e imagens estão mais acessíveis à população e entram todos os dias nas escolas, sem pedir licença, nas mochilas, nos bolsos, nas mãos, enfim, colados aos corpos de alunos, de professores e de todos aqueles que por lá circulam ou trabalham. Basta caminhar com disposição para enxergar e escutar atentamente os jovens pelos diferentes espaços/tempos das escolas de nosso país, quiçá do mundo todo, para nos depararmos com queixas, lamúrias e insatisfações em relação às formas/conteúdos da educação escolar, tal qual ela foi institucionalizada seguindo um determinado modelo de organização engendrado conforme uma lógica operacional que se tornou predominante no que convencionamos chamar de modernidade histórica (SOARES, 2016, p. $84)$.
\end{abstract}

Assistir a série e ter contato com suas discussões é uma forma de suscitar reflexões a docentes, estudantes e outras protagonistas da comunidade escolar sobre nossas relações com as tecnologias. Conteúdo que é presente nos cotidianos escolares, mas não de forma crítica, mas sim como simples ferramenta que auxilia os docentes a apresentar de forma mais descolada certos conteúdos (SOARES, 2016).

As tecnologias que se atualizam constantemente nos dias de hoje precisam ser parte presente nos cotidianos escolares, não só como artefatos didáticos, mas sim como artefatos 
curriculares que promovam discussões, reflexões entre toda a comunidade escolar. Não precisamos nem ir a um futuro próximo distópico como em Black Mirror, vemos em nossos cotidianos exemplos do mal uso das tecnologias digitais, tanto como em simples casos de assédio em redes sociais, ou até casos mais graves de vazamento de dados sem autorização. Sabemos que as tecnologias não são neutras, elas podem ser usadas para os mais variados objetivos, continuar achar que ela é inofensiva e não discutir seriamente seus usos pode tornar que distopias como o Black Mirror se tornar realidade um dia.

A relação entre trabalho e consumo, criação e apropriação presente em 15 Million Merits também é uma oportunidade de discussão nos cotidianos escolares sobre a inexistência da neutralidade, tanto na invenção de novas tecnologias, como na produção mercadológica. Toda criação humana tem um posicionamento político, principalmente as que se dizem neutras. Se não existe neutralidade política, podemos analisar toda forma criativa com alguma intencionalidade estética, ética e política.

Os cotidianos escolares assim também são espaços de criação, não somente dos docentes, mas sim dos discentes que estão criando suas próprias reflexões através da mediação dos docentes. A performance então, faz parte de toda ação ocorrida nos cotidianos escolares. Independente do controle premeditado pelas hegemonias curriculares atuais que através de um conteudismo disfarçado de mérito quer proporcionar ainda mais as desigualdades sociais, se analisarmos a educação no contexto brasileiro contemporâneo, por exemplo, onde cada vez mais a hegemonia curricular é encaminhada em propostas neoliberais de educação. A hegemonia não é um conceito solidificado, mas sim mais um espaço de disputa, assim como a utopia, a hegemonia é um estado a ser alcançado, mas não completamente conquistado, pois a tendência natural da organização social da democracia é funcionar no dissenso. A grande diferença é se a hegemonia que disputamos é inclusiva ou segregadora, no caso das ideias das redes educativas, a proposta das tessituras nos cotidianos escolares busca por horizontalizar a criação de currículos nos cotidianos através das experiências e memórias de todos envolvidos no acontecimento escolar.

A inventividade, está relacionada em nossa sociedade de atributos neoliberais a criação inovadora no mercado, em algo que oferte um produto de consumo diferente no mercado. A 
invenção como forma de crítica, de subversão, de autoconhecimento não tem valor no neoliberalismo caso não tenha uma aplicação de mercado, a alguma competência. Como acontece com Bing em seu discurso, só é visto o caráter rentável, por isso ele é "contratado". A inventividade como criatividade, como forma de sentir o mundo é associado ao campo do lúdico, da brincadeira, da infância, o que é para a lógica do capital, o contrário da produção objetiva do trabalho. Entre a infância, a arte e a loucura, existe um fio criativo de aversão da sociedade capitalista.

Apesar da estrutura cartesiana das cadeiras enfileiradas em sala onde as vezes a criatividade do indivíduo pode ser tolhida, nos dá a impressão de protagonizar somente um tipo de performance, a do professor. Enquanto os estudantes teoricamente estariam ali somente para consumir e se apropriar do que o professor compartilha. Porém, sabemos que mesmo aparentemente "passivos" os estudantes ali estão sendo os protagonistas de seus próprios processos e com o uso de táticas (CERTEAU, 1998) estes também exercem a sua performance na passividade, através dos mais processos cognitivos de bricolagens e principalmente quando o estudante se enuncia para a classe com dúvidas, provocações e comentários. O corpo em criação, em enunciação "é a possibilidade mais genuína da educação e o fundamento ético para conviver na instabilidade irremediável de existir" (NOGUERA, 2018, p. 638).

Os processos educativos então são uma forma de performance, não de um caráter meramente de mise-en-scène, mas da forma de incorporar práticas de insubmissão. Professores e estudantes em sala de aula são artistas e,

pode-se identificar no artista em performance uma máquina de guerra, ou seja, uma força capaz de questionar máximas, borrar clichês, romper e superar os comportamentos impostos e opor-se ao status quo, oferecendo ao espectador novos prismas para estranhar o que, até então, lhe parecia normal. (TINOCO, 2009, p. 240)

Os cotidianos escolares protagonizado por atores (docentes, discentes, funcionários etc) que estão preocupados com uma prática transgressora aos conformes da sociedade do consumo, agem de forma deliberada em tecer redes educativas além das proposições disciplinares e compartimentadoras que fragmentam e flagelam a educação. Não que exista uma 
homogeneidade esta ação de transgressão, muito menos que possamos definí-los por transgressores ou não, mas afirmamos que as multiplicidades são a grande característica desse processo educativo, composta por diversas zonas de inderteminações, em opacidades, que criam tessituras entre os múltiplos acontecimentos nos cotidianos escolares. É o que nos faz pensar no conjunto das práticas do Corpo sem Órgãos de Deleuze e Guattari.

\begin{abstract}
Abre-se a oportunidade de estabelecer o objetivo principal da esquizoanálise deleuziana: um Corpo sem Órgãos ( $\mathrm{CsO})$, em que cada elemento se funde aos demais, as perspectivas individuais escorregam uma na outra, a ponto de sentirem um pelo outro. Expressão tomada de Artaud, o CsO não é uma noção ou conceito, ensina Deleuze, mas um conjunto de práticas. Trata-se de "voltar ao estado de intensidade zero que caracteriza o campo absolutamente aberto de todas as possibilidades, o campo em que podemos, ainda, ser qualquer coisa" (TADEU, 2004, p. 34). O CsO não se define pela ausência de órgãos, nem somente pela existência de órgãos indeterminados, mas pela presença temporária e provisória de órgãos determinados. É a desterritorialização absoluta, a des-subjetivação absoluta, o fazer-se multiplicidade. (TINOCO, 2009, p. 241-242)
\end{abstract}

Se a instituição escola tem como intenção preparar os seus estudantes para a vida, não há melhor forma de se preparar um corpo social ao se interligar ao sentido da vida em rizomas horizontais e não em compartimentações arbóreas. O nossos campos de sentidos, de tessitura de conhecimentos e de expressões não se dão de forma isolada e separada mas sim em um grande plano de imanência onde tudo reflete em tudo, todas as ações se tecem em multiplicidade, criando uma impossibilidade de se analisar o uno e não o coletivo. É o desmembramento da ideia moderna de universalidade falsa e do individualismo competitivo contemporâneo.

No corpo em performance, esse acoplamento se dá tanto nas expressões e deformações do corpo quanto ao lidar com diferentes elementos - objetos, participadores, espaços. O corpo todo, que agora não é mais só o do artista mas o de todos os elementos ambientais e humanos envolvidos, adquire um modo de tocar com os olhos, de olhar com a boca, de comer com o nariz e de ouvir com as mãos. Qualquer tipo de oposição de um sentido em relação aos outros se rompe, em uma imersão na sinestesia, na ativação e consciência do corpo. Ele desenvolve uma maneira de se converter momentaneamente e ser todo ouvidos, todo pés, todo costas, metamorfoseando-se de acordo com a situação. Para um $\mathrm{CsO}$, todas as possibilidades devem ser viáveis e latentes, a transformação é contínua (TINOCO, 2009, p. 242).

A multiplicidade do Corpo sem Órgãos é o que tece uma multiplicidade nos cotidianos 
escolares em práticas que não reproduzam os aparatos de cooptação e apropriação da vida mercadológica, é se aproximar do pensamento de aldeia ao invés do pensamento de cidade, como apontou Noguera (2017). A própria instituição escolar não consegue dar conta da educação de uma toda comunidade, é preciso de uma aldeia inteira para educar uma criança, como diz o provérbio africano. Como o próprio autor complementa:

\footnotetext{
Depois dessas ligeiras considerações, vale a pena registrar as associações que fazemos à cidade e à aldeia, como regimes da linha e da roda, respectivamente. A linha significa uma série de elementos como: exclusão, separação, organização com vistas aos objetivos exteriores, submissão à colonização do tempo, concorrência e competição. Por outro lado, a roda é inclusão, disputa que não visa a competição, a brincadeira como essência vital que não deve ser desprezada. Ou seja, a cidade opera com centro e periferias, sua formação seria em linha. De outro modo, a aldeia é um lugar sem um centro, um território policêntrico por excelência (NOGUERA, 2017, $\mathrm{s} / \mathrm{p})$.
}

A ideia de aldeia, ao contrário da cidade, operaria de maneira horizontal e rizomática, onde todos os seus aldeões compõem uma tessitura coletiva, nos cotidianos, em prol da própria aldeia. A educação na aldeia assim se daria nos próprios cotidianos, onde todos os sujeitos têm responsabilidade e influência na formação do outro. Metaforicamente enquanto na cidade capitalizada e verticalizada, o contato entre os cidadãos se dá de forma bem mais truncada e impessoal por causa das demandas do mundo de produção e consumo.

\section{CONSIDERAÇÕES FINAIS}

Black Mirror é uma série com tantas camadas sensoriais que nos permite diversos caminhos diferentes quando buscamos tecer análise, comentários, críticas e reflexões sobre o seu conteúdo. A controvérsia e o desconforto jocoso são seus carros chefes. A série, mesmo criticando a sociedade altamente tecnológica, consumista faz uso da própria industria capitalista para obter sucesso e retorno financeiro.

15 Million Merits e o restante da série, seriam um dos melhores exemplos para tentar definir o que Deleuze cunhou em imagem-cristal, pois apesar de nos proporcionar reflexões sobre o 
atual, nos é quase impossível não se confundir por todas as camadas do cristal que se juntam em planos virtuais. "O espelho seria a imagem-cristal em estado "puro"" (GUÉRON, 2011, p. 183).

Nos encontrar nesse corredor de espelhos que é a vida contemporânea, acelerada ao extremo devido as tecnologias que tornam a nossa vida cada vez mais porosa, cada vez mais vulnerável as expressões que nos atravessam, é uma grande dificuldade.

A percepção da vida como fluxo efêmero é inerente ao trabalho de performance, transitório por natureza. O resultado é uma escrita breve no espaço e que talvez se eternize na superfície do contato entre as consciências do artista e do interlocutor, depois do encontro de ambos em um só corpo, em multiplicidade (TINOCO, 2009, p. 243).

Abraçar as multiplicidades é o único jeito de não ser tomado por completo pelas indiferenças da nossa vida contemporânea. Enquanto estamos cada vez mais concentrados em nossos egos virtuais, estamos deixando de lado a beleza da autenticidade da vida e assim criando um grande caos em nossa vida coletiva. Encarar o espelho também é uma forma de perceber as diferenças. Se aproveitarmos a tessitura dos rizomas virtuais de nossas tecnologias para nos aproximarmos do que é ser humano em coletivo, ao invés de nos centramos somente no que nos é igual, poderemos de fato não ser definitivamente sermos cooptados pelo sistema.

\section{REFERÊNCIAS}

ALVES, Nilda; BRANDÃO, Rebeca. Repetições e diferenças em cotidianos na/da/com a educação infantil. Em Aberto, Brasília, v. 30, n. 100, p. 95-104, set./dez. 2017.

ALVES, Nilda; FERRAÇO, Carlos Eduardo; SOARES, Maria da Conceição. Michel de Certeau e as pesquisas nos/dos/com os cotidianos em educação no Brasil. Pedagogía y Saberes No. 46 Universidad Pedagógica Nacional Facultad de Educación. 2017.

DELEUZE, Gilles; GUATTARI, Felix. Introdução: rizoma. In: DELEUZE, Gilles; GUATTARI, Felix. Mil platôs - capitalismo e esquizofrenia - vol. 1. Rio de Janeiro: Ed. 34, 1995.

DELEUZE, Gilles; GUATTARI, Félix. Personagens conceituais. In: DELEUZE, Gilles; GUATTARI, Félix. O que é filosofia? Rio de Janeiro: Editora 34, 1992. 
GUERÓN, Rodrigo. Da imagem ao clichê, do clichê à imagem: Deleuze, cinema e pensamento. Rio de Janeiro: NAU editora, 2011.

NOGUERA, Renato. Cidade ou Aldeia? Trabalho ou Brincadeira? Revista cosmo e contexto. 2017.

NOGUERA, Renato; BARRETO, Marcos. Infancialização, ubuntu e teko porã: elementos gerais para educação e ética afroperspectivistas. Childhood \& philosophy, rio de janeiro, v. 14, n. 31, set.-dez. 2018.

NOGUERA, Renato. O poder da infância: espiritualidade e política em afroperspectiva. Momento - Diálogos em Educação, ABNT, v. 28, n. 1, p. 127-142, abr. 2019.

SOARES, Maria da Conceição Silva. O audiovisual como dispositivo de pesquisas nos/com os cotidianos das escolas. Visualidades, [S.1.], v. 14, n. 1, ago. 2016.

TINOCO, Bianca. O corpo presente e o conceito ampliado de performance. Salvador. $18^{\circ}$ ANPAP, 2009. 